\title{
Key Actors In The Mobile Telephone Industry: Feature Phone Years And The Rise Of Nokia
}

Pankaj Nagpal, University of Puerto Rico, Puerto Rico, USA Kalle Lyytinen, Case Western Reserve University, USA

\begin{abstract}
We use historical data to study the feature phone (as different from smart phone) years of the mobile phone industry. This study relates to the years 1994 to 2004, at a time when the industry grew to a landmark of one billion mobile phones cumulative sales worldwide. Actor Network Theory (ANT) is used as a lens to understand the key alliances between selected mobile phone companies and other actants. In line with ANT, actants include consortia, service providers, and IT vendors. The leading mobile phone companies- Nokia, Samsung, and Motorola, display a number of characteristics and actions that have implications for the current and future state of the market. The study demonstrates the explanatory power of ANT. It is important to understand the earlier years of the industry to understand its current state, particularly with reference to Nokia and Samsung. The notion of path dependence suggests that these actors continue to leverage, or be weighed down, by their strengths and weaknesses traced back in history to feature phone years.
\end{abstract}

Keywords: Mobile Phones; Strategy; Alliance; Actor Network Theory; Nokia; Motorola; Samsung

\section{INTRODUCTION}

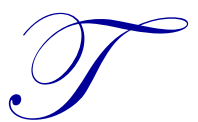

he study examines the early years of the mobile phone industry, through a study of leading mobile phone companies, and their alliances with key technology vendors. Actor Network Theory (ANT) (Latour, 1996) is used as lens to understand the alliances and firm strategy. We draw on historical data on the mobile phone and related industries. In the feature phone era, broadly defined as the years 1994 to 2003, worldwide mobile phone sales grew at 20\% per annum and reached 520 million units in 2003 (Lindholm \& Keinonen, 2003). Growth was driven by first time buyers in emerging markets, and replacement demand in developed markets. In addition to annual growth, there was a nearly continuous quarter-on-quarter growth till the year 2003. This was symptomatic of a relatively benign stage in the industry, as compared to later eras. Around this time, smart phones or 'converged handheld devices' (Stafford \& Gillenson, 2003) started to appear in the market. Therefore, we study 10 years up to 2003 defined as the era of feature phones. The study of this era has several implications for later stages of the market, viz. the smart phone era. In a related paper, we analyze these later eras. Recent developments suggest new developments with additional complexity and integration of hardware and software. Google and Microsoft, which have provided Android and Windows Phone operating systems for mobile phones, also introduced their own hardware devices.

Mobile phones are based on complex and capital intensive technologies, which are sourced through extensive alliances (Ghemawat, 2003). These alliances have been conceptualized as networks of actors, and studied through the lens of actor network theory (ANT) (Gao, 2005). In these networks, dominant standard emerges through interplay of firm strategies and technologies (Suárez \& Utterback, 1995).

Given the extant emphasis on firm level analyses such as the resource based view (Das \& Teng, 2000) in literature, there is a need for an assessment of the role of alliances. In this paper, we study the role of strategic alliances in the mobile phone industry through the lens of ANT. The paper addresses the research question: What are 
the key actors or actants in the mobile phone industry, and how have their alliances affected success (or limitations)? We analyze historical data on alliances, for leading mobile phone companies and selected actors in related industries. The article is organized as follows. We start with a background on the industry and actor network theory. This section is followed by analyses of companies and selected consortia. The article concludes with discussion, limitations and suggestions for future research.

\section{INDUSTRY BACKGROUND}

The key players in the mobile phone industry in 1994 to 2004 were Nokia, Motorola, Ericsson, Samsung, and Siemens. All these companies are multinational in scope, and are active in the current era. Nokia, Motorola, Ericsson, and Siemens were also telecom infrastructure or network manufacturers. Service providers and Information Technology (IT) companies are also major components of the mobile phone industry 'actor network' of ANT. Service providers are the key link with customers, although (with some exceptions) their regional scope is a limiting feature when compared to mobile phone companies, most of which operate worldwide. IT hardware and software companies are the other, hitherto under researched, players in this network. Software companies, such as Microsoft and Google, have been active in the mobile phone industry (Barnes, 2002). Microsoft extended its Windows operating system to Windows Mobile for mobile phones. Windows CE development started in the nineties, with a transition to Windows Mobile in 2003. The leading standard in these years was Symbian, a consortium led by Nokia.

\section{Firms and Market Shares}

Nokia, Motorola, and Ericsson dominated the industry well into the 1990s, until new entrants reshaped the market. Nokia, Motorola, Samsung and Siemens were the leaders by worldwide market share. Their share of worldwide mobile phone shipments were $34.7 \%, 14.5 \%, 10.5 \%$, and $8.4 \%$ respectively, in 2003 . After the spinoff of Ericsson phones, Sony Ericsson had a worldwide share of 5.1\%. (Source: Gartner Dataquest, 2004). In second quarter of 2004, Nokia's market share dropped to $29.3 \%$. Gains were made by the major firms, with Samsung (14.6\%) inching closer to Motorola (15.3\%). Given these trends, Samsung was widely expected to overtake Motorola.

In order to gain an understanding of the industry over a relatively long period of time, we compiled the data on worldwide market shares using various sources. These are shown in Figure 1 (Source: Gartner, Company Annual Reports). The key characteristic is the reversal of positions between Motorola and Nokia, in the late nineties. Ericsson also showed a decline in these years. The other gainers were Samsung, and to some extent, Siemens.

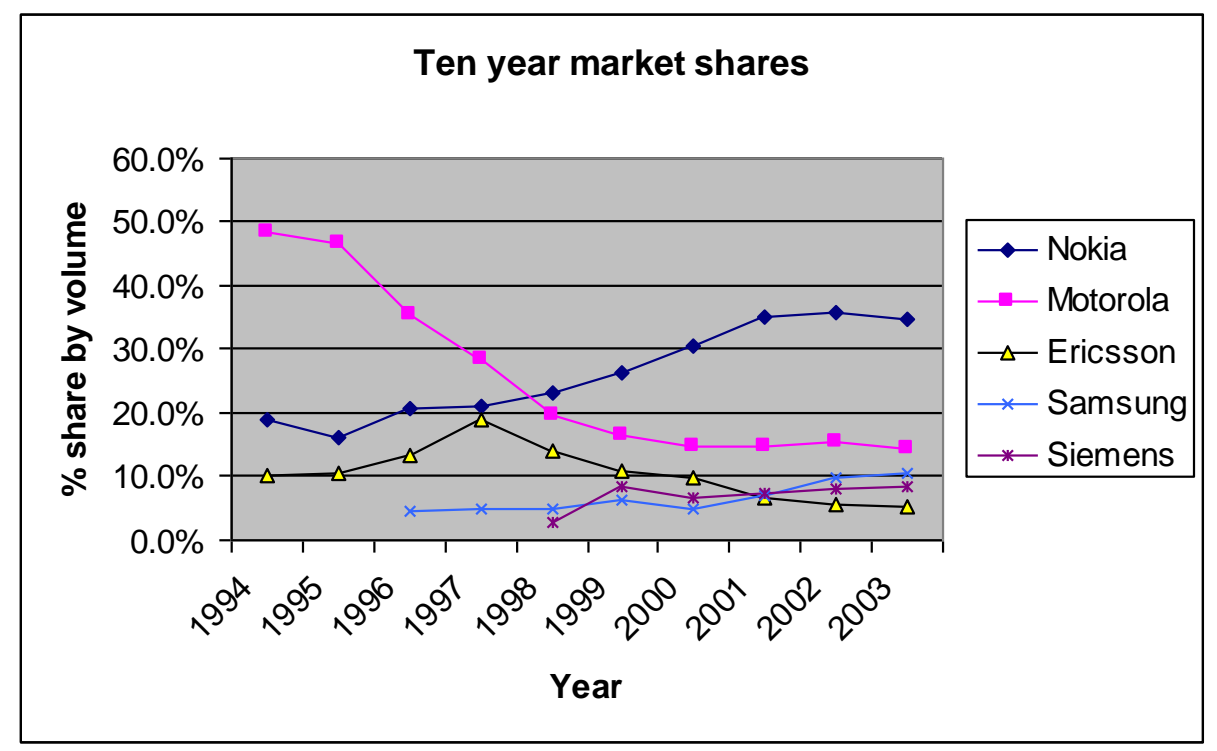

Figure 1 


\section{THEORY, FRAMEWORK AND LITERATURE}

We draw on Actor Network Theory (ANT) to study the key alliances of select mobile phone companies. Developed by Latour (1996) and Callon (1986), social and technological worlds are viewed simultaneously in this theory. ANT has been used widely to study IT artifacts, and actors in the telecom industry (Gao, 2005). A key characteristic of ANT is that the researcher remains impartial "between actors engaged in controversy" (Callon, 1986). This lens allows the consideration of companies, and their key characteristics, such as technologies or standards to be considered in a holistic analysis. The latter are called actants, and include the traditional actors, as well as what are usually considered as passive artifacts in literature. In this ensemble of technical and social artifacts, the actants are considered as part of a network. The actant could have some interests, or simply display some behaviors that are relevant to the network. Well known actants in the telecom industry are standards, IT vendors, and wireless carrier companies. Actor network theory has been applied in Information Systems (IS) research (Hanseth, Aanestad, \& Berg, 2004), and particularly to new telecom products such as Personal Digital Assistants (PDA) (Allen, 2004) and new telecom standards in China (Gao, 2005). This literature has stressed the role of technology (Allen, 2004) and standards (Gao, 2005).

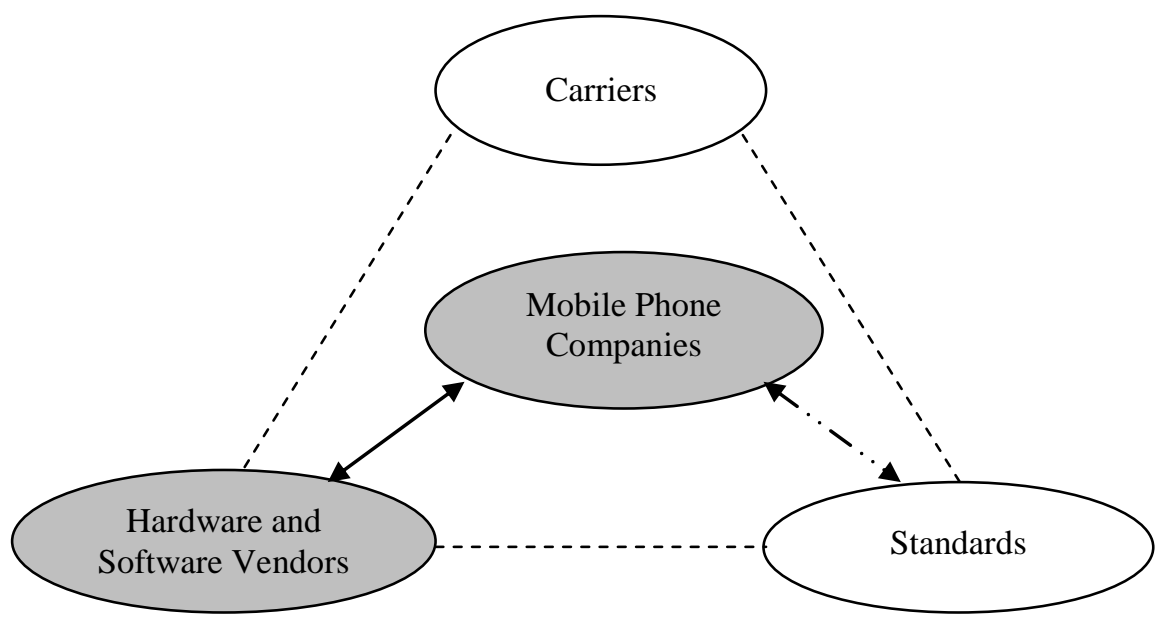

Figure 2: ANT Framework

The framework is shown in Figure 2, with key actors shown in the ovals. Mobile phone companies are conceptualized at the center of actor network. Additional actors or actants are carriers, standards and technology vendors. The arrows show alliances in the network. We study the dyadic alliances that involve mobile phone companies and IT vendors on the left hand vertex. Note that several types of alliances exist; 2 way alliances, 3 way alliances, or even higher orders. In this paper, our focus is on 2 way alliances between phone companies and IT vendors. We also discuss Symbian, an alliance involving multiple mobile phone companies. A key operating system, and competitor to Symbian was Microsoft Windows for mobile. Hence, the left vertex of the triangle is worthy of research interest, having been an under researched area. The bold line shows the focus of our paper.

In the next section, we discuss the mobile phone firms and their key alliances.

\section{ANALYSES}

Here we focus on the largest firms, and their alliances. In addition to these firm level alliances, we also review industry level alliances that span the industry ecosystem. These alliances are summarized in Table 1. Detailed announcements that include the year of announcement, relevant firms, organizational form, and product category under the alliance, are available from authors. Industry wide alliances are discussed later in this section. 
Table 1: Actor Networks for Select Mobile Phone Companies, 1994-2004

\begin{tabular}{|l|l|l|}
\hline Actor & Operating System Consortium or Vendor & \multicolumn{1}{c|}{ IT vendors } \\
\hline Nokia & Symbian & $\begin{array}{l}\text { Oracle, HP, Cisco, 3Com, Warner Music, Bluetooth (IBM and } \\
\text { Intel alliance), Philips NFC, Real Networks. }\end{array}$ \\
\hline Motorola & Symbian till 2003, left and joined Windows & Sun, Cisco, Real Networks \\
\hline Samsung & $\begin{array}{l}\text { Windows, also joined Symbian in 2003, } \\
\text { Microsoft }\end{array}$ & Philips NFC, Real Networks \\
\hline Ericsson & Symbian & Sybase, Cisco, Mannesmann, Bluetooth, Real Networks \\
\hline Siemens & License from Motorola for 3G & Sun, Scientific Atlanta, Real Networks \\
\hline
\end{tabular}

\section{Nokia: The New Leader}

Nokia became the leading player in the worldwide mobile phone market in 1998, overtaking Motorola. The company had a strong focus on the mobile phone business, which constituted more than $60 \%$ of overall company sales in 2003. Given its size and prominence, it played a key role in setting standards in the industry. Nokia's technology related strengths were complemented with strong marketing and consumer orientation. As shown in Table 1, our data suggests a dense network of alliances for Nokia. Nokia also played a major role in setting industry standards. This standard setting role was orchestrated through Symbian, an industry consortium. As the market leader, it took potential competitors from other industries, such as software, very seriously. In addition to its role in Symbian (discussed later), Nokia actively promoted additional standards and alliances to proactively compete with nascent threats, such as Microsoft. In 1999, when it was established as a clear leader, Nokia tried to strengthen the links between Symbian and Palm, thus creating a "de facto standard" for mobile Internet (Sorkin, 1999). These bold strategies further strengthened Nokia' position, as it continued to gain market share in the following years. In corporate and consumer services, Nokia developed alliances with Oracle and Warner Music, respectively. Nokia continued to lead the global market, although there were some fluctuations in market share around the $35 \%$ level.

\section{Motorola: The Past Leader}

Motorola was considered the inventor of mobile phone, with the DynaTAC in 1984 (Source: Motorola). A more diversified firm as compared to Nokia, Motorola was considered a conglomerate in the electronics industry. This range of products strengthened the firm in that it had many technologies in-house. The company was well known for its strengths in engineering.

Motorola was a clear leader in mobile phones until 1997, with as much as half of the market in the early to mid nineties. Notably, phone volumes continued to grow, and it was only a slower growth that led to lower market share. It seems that Motorola was more interested in alliances relating to infrastructure and Internet. In 1994, the firm set up a joint venture with a service provider. Although such joint ventures had been used as vehicles to sell or lease equipment to service providers, which was not the case: Motorola invested in the license. There were similar infrastructure-related alliances with Sun Microsystems and Cisco. Its keen interest in mobile Internet, which took time to take off, was a setback for Motorola. In this respect, some of its technology strategies were probably ahead of their time. A notable innovation was the clamshell style RAZR model, introduced in 2004.

\section{Samsung: The Emerging Leader}

Samsung's success in this era was driven by its strengths in technology, design, and marketing. The firm shared similarities with Motorola and Ericsson, in terms of having a large range of technologies related to mobile phones. Samsung also had a large and growing consumer electronics business. This combination of technologies and marketing expertise was perhaps unique to Samsung, among mobile phone companies. This would explain the gains in market shares shown in Figure 1. With telecommunications contributing one-third of sales, the company was in a position to ally with a large number of firms, and yet have an impact. Samsung used wide ranging alliances that went beyond mobile phones. The best example is alliances with Microsoft, which include electronics and mobile phones.

Samsung concentrated on high end products, with the avowed strategy of entering with new models when there were 'discontinuities' in the market. Aggressive alliances with US service providers also helped increase 
market share. It was also one of the first major mobile phone companies to introduce camera phones. The information on Samsung's alliances is relatively sparse, prior to the year 2000. Samsung was the first major mobile phone company to use Microsoft Windows CE software, giving a fillip to this standard. However, it joined Symbian in 2003. Its shareholding was nominal, and it was only a licensee of Symbian software.

\section{Ericsson}

Ericsson had been historically known for its strengths in industrial and infrastructure telecom. Mobile phones made up only 10\% of its earnings in 2003 (this was the share of earnings from joint venture with Sony). However, its market share grew till 1997, after which it started falling. The trend continued in spite of a joint venture with Sony. The reference sources suggest that there were few alliances made by Ericsson. In 2000, Ericsson started an alliance with Sybase, for mobile commerce applications. In 2004, the firm began a strategic alliance with Cisco to work on mobile Internet. Ericsson hived off its mobile phone business into a joint venture with Sony, and appeared to increase focus on networks. The result was not entirely satisfactory, as Sony Ericsson market share continued to slide. However, it was a limited technology success, licensing its technology to smaller mobile phone companies. Sony Ericsson was overtaken by Samsung and Siemens well before 2003.

\section{Siemens}

The firm was the most diversified among the analyzed companies, with mobile phones contributing less than $10 \%$ to its sales. Given its strengths in electricals and electronics, mobile phones seemed to be an auxiliary investment in telecom, a growth area in the nineties. In terms of alliances, the company was involved in a marketing alliance with Sun Microsystems and Scientific-Atlanta to sell network equipment to cable and telephone companies. In later years, it licensed some technology from Motorola in its multimedia phones. In this respect, Siemens was seen as an infrastructure firm which had some side interest in mobile phones. It also appeared to have a focus on Asian countries. Its long history in these countries gave it an image of reliability, enhanced by its involvement in design and manufacture of networks, e.g., developing new mobile standards in China (Olavsrud, 2003).

\section{Industry Level Alliances}

In this section, we discuss the key alliances that relate to mobile phone operating system. In addition to mobile phones, these systems control mobile devices such as PDAs. Pioneered by Psion of UK, the PDA market attracted Nokia and Apple. Nokia 9000 Communicator created the "PDA phone" (Wikipedia) as the precursor of the current smart phone. In this era, Symbian and Microsoft were the key players. Microsoft licensed Windows CE software to extend its strength in desktop computers. Large telecom service providers also developed a standard called SavaJe, as discussed later. Samsung and Motorola worked across Symbian and Microsoft technologies. Notably, Samsung started licensing with Microsoft, and joined Symbian later.

\section{Symbian}

Symbian was the de facto standard for the industry, with Microsoft as the challenger. Symbian was started as an 'open source' consortium in 1998, with Ericsson, Nokia, Motorola and Psion as its members. Sony and Sanyo were the first major licensees. Siemens and Samsung joined as shareholders in 2002 and 2003, respectively. Motorola left the alliance in 2003, although it continued as a licensee. Finally, with Psion, the leading shareholder, selling its stake to Nokia in 2004, Nokia's shareholding rose to $47.9 \%$. This was seen as a turning point in that Symbian was no longer seen as an industry consortium (Wearden, 2004) but dominated by Nokia. However, it was mentioned as a "powerful competitor" in 2003. Symbian volumes continued to grow slowly till 2010, albeit accompanied with falling market share (Wikipedia). 


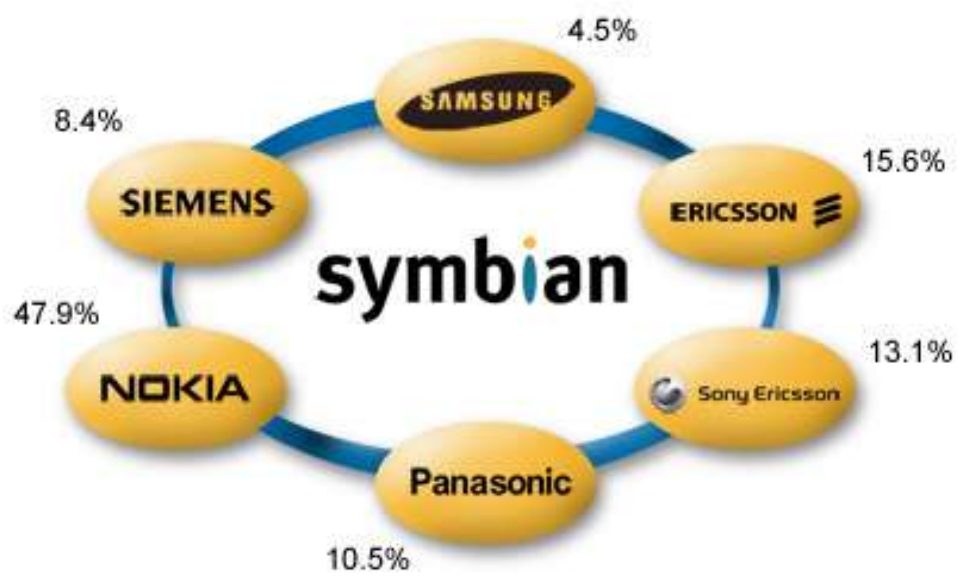

Figure 3: Symbian Shareholders: 2004

(from company website)

Nearly all mobile phone companies licensed the Symbian software, in 2004. Some of them, such as LG and Lenovo, were not shareholders.

Windows

Starting with research projects in 1990, Microsoft operating system Windows CE was available in 1996 (Wikipedia). This was followed by a series of Windows Mobile versions. It acquired a share of $11 \%$ of smart phone market in 2004. In spite of limited success, Microsoft continued to invest and gained the interest of most mobile phone companies. However, it was not central to any company's handset range, in that they licensed Symbian as well as Windows. Its biggest success came many years later, when Nokia launched the Lumia model exclusively with Windows.

SavaJe

Vodafone and Orange teamed up in 1999 to develop an 'open' Java based standard, SavaJe, which was joined by T-Mobile later. According to the SavaJe website, service providers as well as mobile phone companies could license the technology. Its advantage was supposedly a high degree of customization, according to the firm. Most major mobile phone firms were licensees of Symbian, and only smaller shareholders, such as Samsung, were expected to try SavaJe. Ultimately, only LG licensed the SavaJe technology, and the standard did not gain traction in the market. It was bought by Sun in 2007 (Fehrenbacher, 2007).

\section{DISCUSSION AND CONCLUSION}

This paper traces the alliances in the actor network, with a focus on mobile phone companies and IT vendors. In addition to our observations on the individual companies, we synthesize the results in this section. First, success of Nokia has been linked to many factors, over and above its size. Its leadership of Symbian gave it a vantage position to influence the actor network. It was vigilant to note the competition in 'related' technologies, and strengthened Symbian through adding Palm to the alliance.

Looking at Samsung and LG, it appears that these challenger firms leveraged strengths in marketing from their consumer electronics experience. They also looked outside Symbian to jockey for advantage. Samsung was the first major firm to use Microsoft mobile standards, and LG was similarly amenable to SavaJe. In other words, is the use of a new standard a vehicle for a challenger? Or is it simply a characteristic of these 'new' firms? We cannot answer the question using this set of actors.

We used ANT to understand these alliances. At a broad level, we distinguish mobile phone companies, service providers, and technology firms as the major groups. Key exemplars are Symbian, SavaJe, and Microsoft. 
The growing ownership of Nokia in Symbian ultimately had mixed results, with other mobile phone companies seeing it less as an open industry consortium (Wearden, 2004). These results suggest that networks can actually weaken, when an individual actor's influence crosses a threshold.

\section{Limitations and Future Research}

There are several limitations, theoretical as well as empirical. Path dependence (David, 1994) is an alternative lens to study this data. We focus on selected actors, as shown in the shaded area in Figure 2. The recent influential roles of Google and Apple, an operating system and mobile phone company, respectively, tend to confirm that analyses need to focus on this 'vertex' of the actor network. This leaves out a key actant, standards, covered in ANT literature (Gao, 2005). The empirical limitations relate to data availability. The paper depends on use of secondary data. In this respect, the actions of players are understood and interpreted solely through secondary data, which is a key limitation. We do not collect additional primary data. We covered a ten year time span from 19942003; however, there was sparse data for earlier years. Other limitations have to do with comparability of data from different company annual reports. Nokia and Microsoft, which were rivals in the feature phone era, allied together in recent years to work on Nokia Lumia. This alliance is an interesting area of future research.

\section{AUTHOR INFORMATION}

Pankaj Nagpal, Ph.D. CISA is an Assistant Professor of Accounting at the University of Puerto Rico. E-mail: pxn18@alumni.case.edu (Corresponding author)

Dr. Kalle Lyytinen is Wolstein Chair of Design and Professor at Case Western Reserve University. E-mail: kalle.lyytinen@case.edu

\section{REFERENCES}

1. Allen, J. P. (2004). Redefining the network: enrollment strategies in the PDA industry. Information Technology \& People, 17(2), 171-185.

2. Barnes, S. J. (2002). The mobile commerce value chain: analysis and future developments. International Journal of Information Management, 22(2), 91-108.

3. Callon, M. (1986). Some elements of a sociology of translation: domestication of the scallops and the fishermen of St Brieuc Bay. In J. Law (Ed.), Power, action and belief: a new sociology of knowledge? London: Routledge.

4. Das, T. K., \& Teng, B.-S. (2000). A Resource-Based Theory of Strategic Alliances. Journal of Management, 26(1), 31-61.

5. David, P. A. (1994). Why are institutions the carriers of history?: Path dependence and the evolution of conventions, organizations and institutions. Structural Change and Economic Dynamics, 5(2), 205-220.

6. Fehrenbacher, K. (2007). Sun sets on SavaJe. Gigaom. Retrieved from http://gigaom.com/2007/04/13/sunsets-on-savaje/

7. Gao, P. (2005). Using actor-network theory to analyse strategy formulation. Information Systems Journal, $15(3), 255$.

8. $\quad$ Ghemawat, P. (2003). The Forgotten Strategy. Harvard Business Review, 81(11), 76-87.

9. Hanseth, O., Aanestad, M., \& Berg, M. (2004). Guest editors' introduction: Actor-network theory and information systems. What's so special? Information Technology \& People, 17(2), 116-123.

10. Latour, B. (1996). Aramis or the Love of Technology. Cambridge, MA: Harvard University Press.

11. Lindholm, C., \& Keinonen, T. (2003). Mobile Usability: How Nokia Changed the Face of the Cellular Phone. New York, NY: McGraw-Hill, Inc.

12. Olavsrud, T. (2003). Siemens, Huawei Form 3G Venture in China. InternetNews.com, (August 29, 2003). Retrieved from http://www.internetnews.com/wireless/article.php/3070501

13. Sorkin, A. R. (1999). Palm Computing and Wireless Makers Form Partnership. New York Times, Oct. 14, 1999. Retrieved from http://www.nytimes.com/1999/10/14/business/palm-computing-and-wireless-makersform-partnership.html 
14. Stafford, T. F., \& Gillenson, M. L. (2003). Mobile commerce: what it is and what it could be. Communications of the ACM 46(12), 33-34.

15. Suárez, F. F., \& Utterback, J. M. (1995). Dominant designs and the survival of firms. Strategic Management Journal, 16(6), 415-430.

16. Wearden, G. (2004). Nokia grabs Psion's Symbian stake. CNET News. Retrieved from http://news.cnet.com/2100-1039_3-5155434.html

17. Wikipedia. Mobile operating system Retrieved July 1, 2012, from http://en.wikipedia.org/wiki/Mobile_operating_system\#Historical_software_platforms

18. Wikipedia. Personal digital assistant Retrieved July 1, 2012, 2012, from http://en.wikipedia.org/wiki/PDA

19. Wikipedia. Windows Mobile Retrieved 1 July, 2012, from http://en.wikipedia.org/wiki/Windows Mobile 